\title{
Avaliação do efeito de faixas adicionais de subida em segmentos de rodovias de pista simples
} Impact evaluation of climbing lanes on two-lane rural highways

\author{
Frederico Amaral e Silva ${ }^{1}$, José Elievam Bessa Júnior ${ }^{2}$, Anáiram Lima Costa ${ }^{3}$, André Luiz Cunha ${ }^{4}$, \\ Aline Ferreira Andalício ${ }^{5}$, Diego Milli da Costa Velho ${ }^{6}$, Veridianne Soares Nazareth ${ }^{7}$
}

\author{
1Universidade Federal de Minas Gerais, Minas Gerais - Brasil, fred.amarals@gmail.com \\ 2Universidade Federal de Minas Gerais, Minas Gerais - Brasil, elievam@etg.ufmg.br \\ 3Universidade de São Paulo, São Paulo - Brasil, anairamcosta@usp.br \\ 4Universidade de São Paulo, São Paulo - Brasil, alcunha@usp.br \\ ${ }^{5}$ Concessionária BR-040 S/A - Via040, Minas Gerais - Brasil, alineferreiraandalicio@yahoo.com.br \\ ${ }^{6}$ Concessionária BR-040 S/A - Via040, Minas Gerais - Brasil, diego.milli@invepar.com.br \\ ${ }^{7}$ Concessionária BR-040 S/A - Via040, Minas Gerais - Brasil, veridianne.nazareth@invepar.com.br
}

\section{Recebido:}

14 de abril de 2020

Aceito para publicação:

1 de junho de 2020

Publicado:

20 de agosto de 2021

Editor de área:

Flávio Cunto

\section{Palavras-chave:}

Nível de Serviço.

HCM.

Simulação de Tráfego.

\section{Keywords:}

Level of service.

HCM.

Traffic simulation.

DOI:10.14295/transportes.v29i1.2359

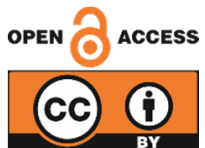

\begin{abstract}
RESUMO
O novo método do Highway Capacity Manual (HCM) para calcular a capacidade e o nível de serviço de rodovias de pista simples deverá ser, provavelmente, baseado na Densidade de Veículos em Pelotões (FD). No Brasil, há poucos estudos que determinam o impacto de faixas adicionais em rodovias de pista simples, sobretudo envolvendo $F D$, que é o objetivo geral deste trabalho. Para isso, foi obtido um conjunto de dados de tráfego em segmentos de rodovia para calibrar e validar o simulador de tráfego VISSIM. Com uma versão recalibrada do simulador, foram gerados dados de tráfego em segmentos viários hipotéticos com e sem faixas adicionais, com os quais foram ajustados modelos de tráfego fluxo $\times F D$. Os resultados da análise dos modelos indicaram que a proposta deste trabalho produziu valores de nível de serviço e de $F D$ mais aderentes aos valores que foram observados em campo.
\end{abstract}

\section{ABSTRACT}

The new method of the Highway Capacity Manual (HCM) to calculate the capacity and the level of service of two-lane highways will likely be based on Follower Density (FD). In Brazil, few studies have determined the impact of climbing lanes on two-lane highways, especially involving $F D$, which is the objective of this paper. To achieve this goal, a set of traffic data was obtained from highway segments to calibrate and validate the traffic flow simulator VISSIM. With a recalibrated version of the simulator, traffic data were generated for hypothetical highway segments with and without climbing lanes, with which flow-FD relationships were adjusted. The results of this analysis indicated that the models proposed in this work produced the level of service and FD values more adherent to the values observed in the field.

\section{INTRODUCÃO}

A fluidez e a segurança operacional em rodovias de pista simples podem ser prejudicadas caso existam rampas acentuadas e longas que provoquem uma brusca redução da velocidade da corrente de tráfego. Nesses locais, as faixas adicionais de subida podem ser implantadas. Consistem em uma terceira faixa de tráfego, complementar, para o uso, principalmente, de veículos pesados com baixo desempenho veicular, com o objetivo de facilitar a ultrapassagem dos veículos mais rápidos com segurança e rapidez, sem usar a faixa no sentido oposto. As faixas adicionais, 
se corretamente implantadas, reduzem a formação dos pelotões e aumenta o tempo de viagem, melhorando o nível de serviço no segmento viário (AASHTO, 2011). Possuem menor impacto ambiental e um menor custo de implantação em relação às obras necessárias para duplicação uma rodovia (Melo e Setti, 2007).

Do ponto de vista operacional, o HCM é o documento mais difundido no mundo para calcular a capacidade e o nível de serviço de componentes viários. Em 2016, foi publicada a 6 edição do manual, denominado de HCM-6 (TRB, 2016). Contudo, ainda não foi disponibilizado o novo capítulo referente às rodovias de pistas simples, embora tenha sido publicado um relatório que indica como será esse novo método, desenvolvido no âmbito do National Cooperative Highway Research Program (NCHRP), denominado de Project 17-65 (Washburn et al., 2018). A Densidade de Veículos em Pelotões (Follower Density - FD) deverá ser a nova medida de serviço utilizada pelo HCM voltada para esse tipo de rodovia.

Na literatura, é possível encontrar métodos alternativos ao HCM para avaliar rodovias de pista simples, como é o caso da Alemanha (FGSV, 2005) e da Espanha (Moreno et al., 2018; Moreno, 2020). 0 uso do HCM sem que seja adaptado para as condições brasileiras tem culminado na subestimação dos níveis de serviço calculados (Utimura et al., 2007; Pereira e Bessa Jr., 2017). 0 método proposto no NCHRP Project 17-65 foi desenvolvido com dados coletados em rodovias americanas, o que sugere que essa tendência de subestimação pode ocorrer novamente. Sendo assim, o objetivo deste trabalho foi avaliar o impacto das faixas adicionais de subida em rodovias de pista simples, usando FD como medida de desempenho.

\section{FAIXAS ADICIONAIS DE SUBIDA}

Quando se trata da implantação de projetos geométricos de rodovias, incluindo elementos como as faixas adicionais de subida, as diretrizes da AASHTO (2011) vêm sendo as mais utilizadas no mundo. A partir de considerações econômicas, a AASHTO (2011) recomenda a implantação de faixas adicionais de subida a partir de dados como o fluxo de tráfego unidirecional, o fluxo de tráfego de veículos pesados, a velocidade de um veículo pesado típico na rampa ascendente e o nível de serviço. Como esses critérios são estabelecidos a partir das condições observadas em rodovias americanas, é comum adaptá-los para condições locais, como em relação aos fluxos mínimos exigidos para implantação de faixas adicionais de subida em rodovias brasileiras (Melo e Setti, 2007).

Em relação à análise operacional das faixas adicionais, vale ressaltar a evolução que vem ocorrendo com simuladores de tráfego tradicionais, como o AIMSUN (TSS, 2018) e o VISSIM (PTV, 2018), e simuladores desenvolvidos mais recentemente, como o SWashSim (Washburn, 2017), para modelagem de rodovias de pista simples. Simuladores de tráfego também têm exercido um papel fundamental na obtenção de métodos para análise operacional de rodovias, como aqueles presentes no HCM.

Desde a versão de 2000 (TRB, 2000), que foi adaptada para o Brasil (Setti et al., 2011), até a versão atual do manual (TRB, 2016), o método do HCM mudou pouco no que diz respeito à avaliação de segmentos com faixas adicionais de subida (que é considerada uma "rampa específica"). Basicamente, consiste, primeiro, em aplicar o método voltado para segmentos homogêneos (como se não houvesse faixas adicionais) para determinar as medidas de desempenho usadas no cálculo do nível de serviço - a Velocidade Média de Viagem (ATS) e a Porcentagem de Tempo Viajando em Pelotões (PTSF). Em seguida, por meio de fatores de ajuste, são alterados 
os valores previamente calculados para $A T S$ e a $P T S F$, que, respectivamente, aumenta e diminui devido à presença das faixas adicionais.

A FD vêm sendo apontada, em alguns trabalhos (Moreno et al., 2016; Al-Kaisy et al., 2018; Bessa Jr. e Setti, 2018), como uma medida de desempenho em potencial para substituir a ATS e a PTSF como medida de serviço para rodovias de pista simples (sobretudo porque a PTSF é bem difícil de ser obtida diretamente em campo, ao contrário da FD). A FD representa bem as condições da rodovia, sendo também capaz de representar a percepção do usuário e havendo compatibilidade com outros tipos de rodovias. 0 método proposto no NCHRP Project 17-65 (Washburn et al., 2018) leva em conta as faixas adicionais. Além dele, somente um outro no exterior (Al-Kaisy e Freedman, 2011) buscou avaliar o impacto das faixas adicionais levando-se em conta a $F D$ como medida de desempenho.

\section{MÉTODO}

Para atingir a meta traçada do trabalho, foi aplicado o método proposto na Figura 1, que se inicia com a coleta de dados de tráfego, tais como volume, velocidade veicular, headways e massa e potência de veículos pesados, em segmentos de rodovias de pista simples selecionados. Com isso, deve ser possível estimar: (i) as distribuições de velocidades desejadas nos segmentos viários, para fins de modelagem no simulador de tráfego (VISSIM, versão 10); (ii) os modelos de desempenho dos veículos pesados, também para realizar simulações de tráfego; e (iii) um modelo que represente o impacto de curvas horizontais na operação da rodovia.

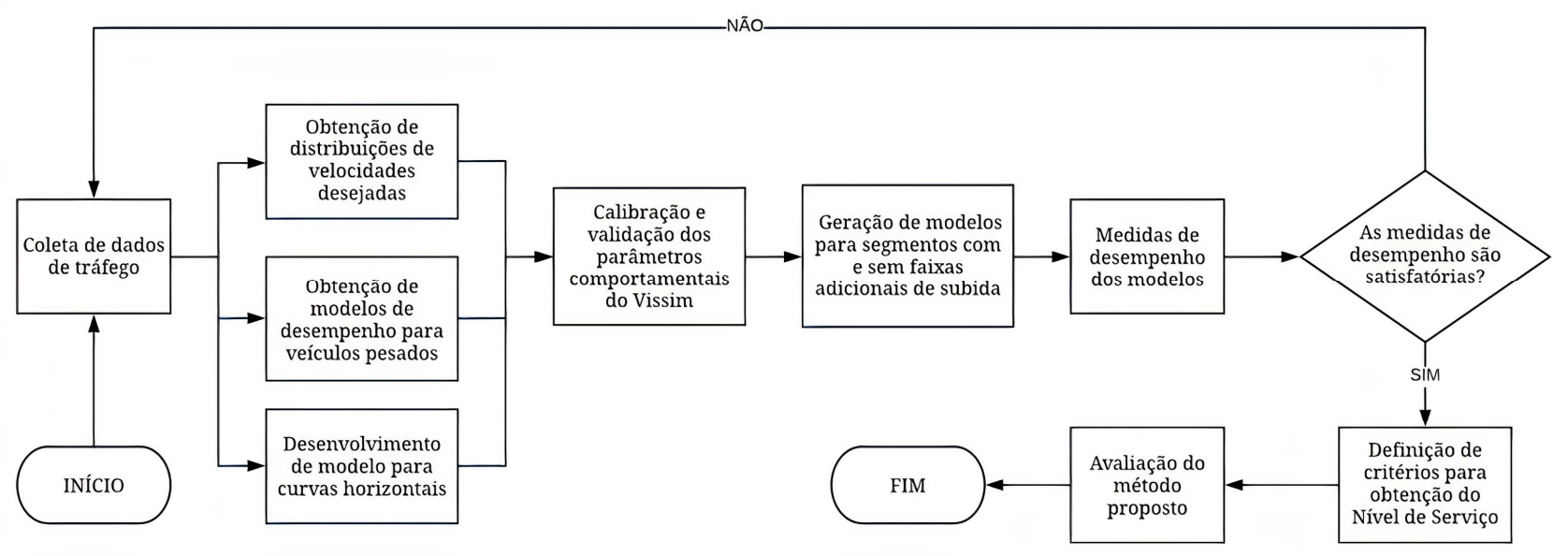

Figura 1. Método proposto para avaliar o impacto de faixas adicionais

Após isso, parte dos dados também é usada para calibrar e validar os parâmetros comportamentais do simulador de tráfego, realizado em duas etapas: (i) a partir de dados de campo; e (ii) por meio de um Algoritmo Genético (AG). Com isso, o simulador deve estar apto para gerar dados em diversas condições de tráfego e de geometria viária, com o objetivo de gerar modelos para segmentos com e sem faixas adicionais. As medidas de desempenho oriundas dos modelos (que, neste artigo, foi a $F D$ ) devem ser comparadas com dados de campo.

Caso as medidas de desempenho obtidas dos modelos sejam consideradas satisfatórias, são definidos novos critérios para obter o nível de serviço. 0 método, então, é avaliado com o objetivo de determinar o impacto na obtenção dos níveis de serviço a partir do uso dos modelos propostos neste trabalho, comparando-os com os níveis de serviço encontrados a partir da proposta do relatório do NCHRP Project 17-65. 


\section{COLETA DE DADOS DE TRÁFEGO}

As coletas de dados de tráfego foram planejadas para se obter um conjunto diverso, em termos de fluxo e de geometria viária dos trechos. Os dados foram obtidos por filmagem em segmentos de, aproximadamente, 10 km, entre os km's 19 e 39; 95 e 105; 130 e 150, nos dias 29 e 30 de março de 2018 e 1 de abril de 2018, todos com velocidades regulamentares acima de $80 \mathrm{~km} / \mathrm{h}$. Outra coleta de dados foi realizada nos trechos entre os km's 288 e 298; e 359 e 399, nos dias 7 e 9 de setembro de 2018. A amostra obtida tinha 177 correntes de tráfego de 15 minutos; dessas, 54 foram coletadas em segmentos com faixas adicionais.

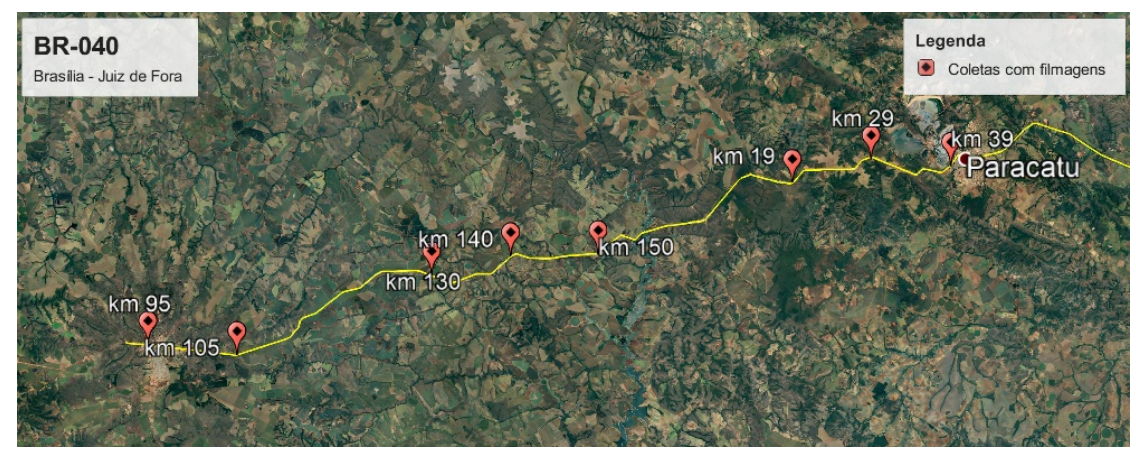

(a)

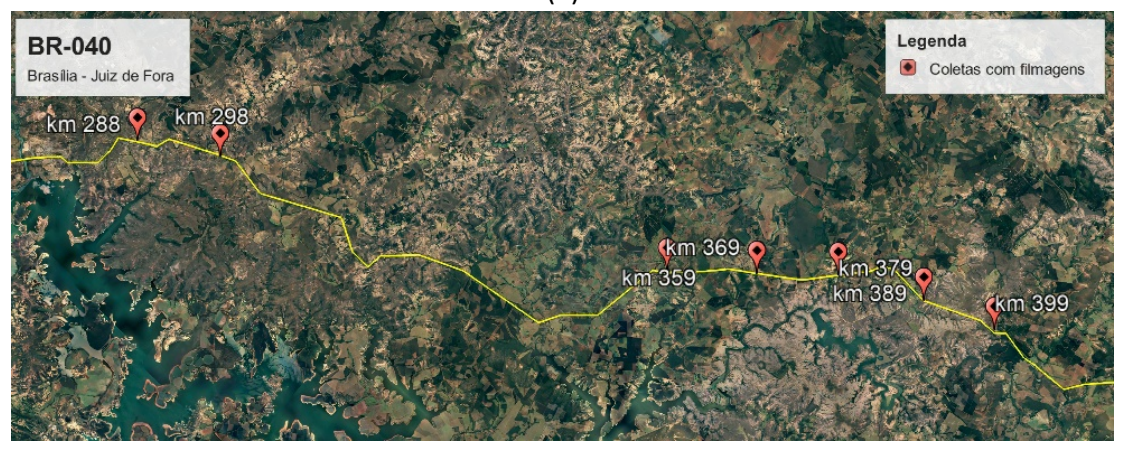

(b)

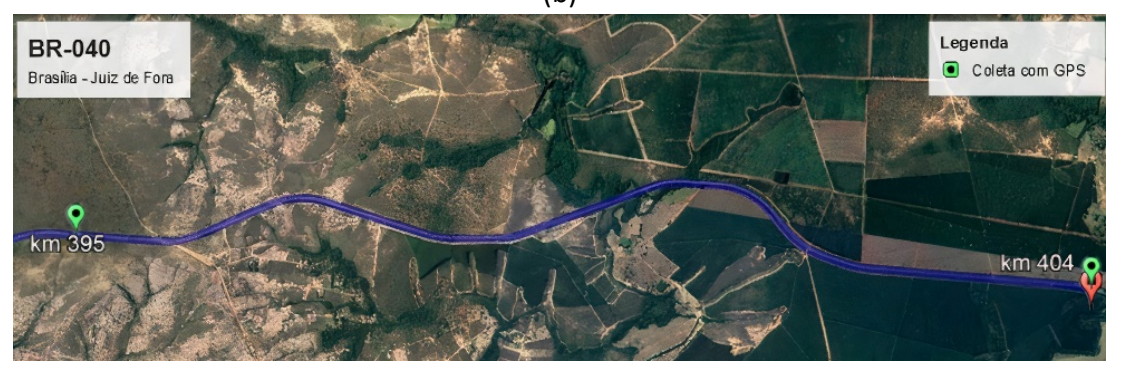

(c)

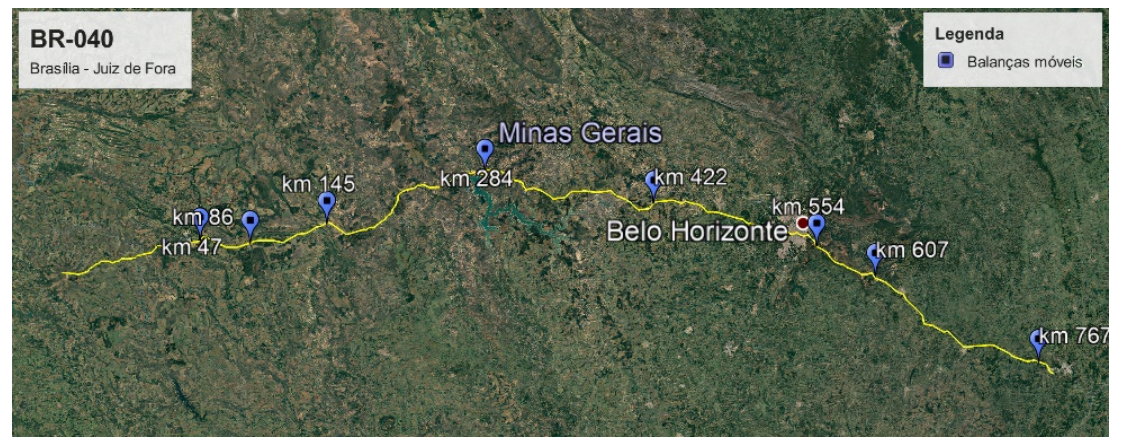

(d)

Figura 2. Marcos quilométricos das coletas com filmagens em março e abril de 2018 (a); em setembro de 2018 (b); com uso de GPS (c); e das balanças móveis (d) 
Foram realizados alguns voos com um quadricóptero portátil (drone) Mavic Pro (DJI, 2017) para registrar as ultrapassagens em campo, com o intuito de obter parâmetros de calibração comportamentais do VISSIM. De acordo com a legislação brasileira (ANAC, 2017), não podem ser realizados voos com mais de $120 \mathrm{~m}$ de altura, o que delimita as observações de trechos de ultrapassagens com comprimento suficiente para observação das manobras. Para corrigir as distorções das distâncias com o drone posicionado em direção ao horizonte, foi feita uma correção (Cunha, 2013) para transformar a perspectiva das imagens como se o Drone estivesse posicionado de forma perpendicular à rodovia.

Uma vez que não há um modelo específico no VISSIM para curvas horizontais, também foi realizada uma coleta de dados, em março de 2019, para obter informações acerca dos comportamentos dos condutores nas curvas horizontais para modelagem no simulador. A coleta foi realizada entre os km's 395 e 404 da BR-040, próximos ao município de Curvelo. Consistiu em acompanhar o trajeto dos veículos leves e pesados no segmento e obter, com um GPS, informações sobre o posicionamento dos veículos.

Foram registrados os percursos de 20 automóveis e 10 caminhões, entre leves, médios, pesados e extrapesados, em curvas de raios entre $414 \mathrm{~m}$ e $905 \mathrm{~m}$, mediana de $559 \mathrm{~m}$ e desvio padrão de $252 \mathrm{~m}$. Foi identificado que a velocidade em curva teve correlação somente com a velocidade em tangente, tendo sido encontrado, com um $R^{2}$ igual a 0,98 , o seguinte modelo:

$$
V_{\text {curva }}=0,95 \cdot V_{\text {tangente }},
$$

em que $v_{\text {curva }}$ é a velocidade média dos veículos na curva horizontal; e vtangente é a velocidade média dos veículos em tangente. Na Figura 2, é possível observar os marcos quilométricos das coletas com filmagens e com o GPS, além da localização das balanças móveis (que registraram dados de massa e de potência usados para estimar o modelo de desempenho de veículos pesados, como citado no item a seguir).

\section{CALIBRAÇÃO E VALIDAÇÃO DO VISSIM}

O VISSIM é um simulador microscópico de tráfego que permite criar diferentes cenários de tráfego com uma abordagem dinâmica e estocástica (PTV, 2018). Possui submodelos comportamentais, como os de car-following, de mudança de faixas, de aceitação de brechas e de desempenho veicular. Cada grupo de parâmetros comportamentais de motoristas inclui inúmeras possibilidades de calibração. Por isso, Hollander e Liu (2008) sugerem que, para determinar aqueles que serão ajustados por algum método, os parâmetros sejam organizados em grupos, como aqueles que podem ser obtidos em campo e outros que não devem ser considerados para calibração (como exemplo, aqueles que influenciam pouco nos dados de saída). Essa recomendação foi levada em consideração neste trabalho.

\subsection{Distribuições de velocidades desejadas e modelos de desempenho veicular}

As distribuições de velocidades desejadas foram obtidas de dados pontuais, nas entradas e saídas das seções dos segmentos viários filmados. Com esses dados, foi possível observar os veículos que estiveram em pelotões, com headways iguais ou menores que 2,5 segundos (Washburn et al., 2018). Os veículos que foram observados com headways maiores foram considerados livres, e que, teoricamente, trafegam na velocidade desejada. Na Figura 3, é possível observar as distribuições de velocidades desejadas estimadas para os segmentos viários analisados. Essas distribuições foram consideradas, no VISSIM, para todos os tipos de veículos. 
Se os veículos pesados não conseguem atingir essas velocidades desejadas mesmo quando o fluxo de tráfego é baixo, deve-se ao modelo de desempenho desses veículos.

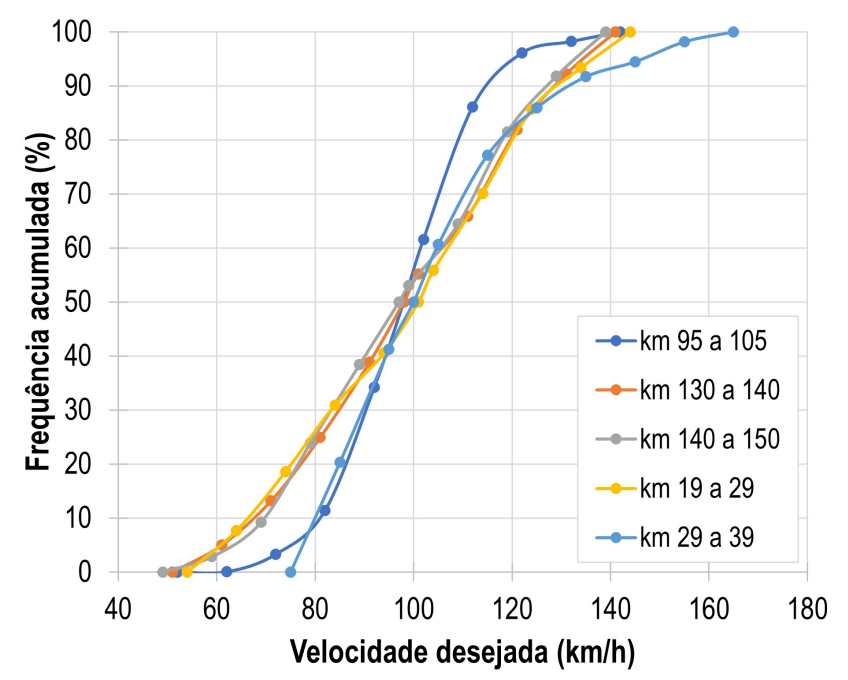

(a)

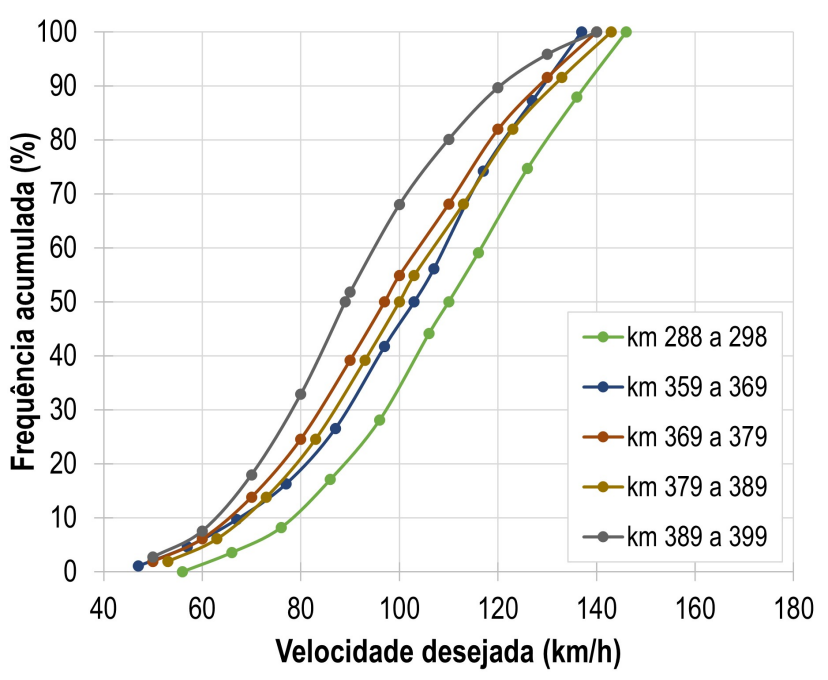

(b)

Figura 3. Distribuições de velocidades desejadas nos segmentos da BR-040 observados em março e abril de 2018 (a) e em setembro de 2018 (b)

O modelo de desempenho dos veículos pesados para inclusão no VISSIM foi calibrado para quatro categorias: leves, médios, pesados e extrapesados. Foram desenvolvidas distribuições de frequência da massa desses veículos a partir de dados coletados em balanças móveis posicionadas entre o km 47 e o km 767 da BR-040 (Figura 2). Foram também desenvolvidas distribuições de frequência da potência dessas quatro categorias veiculares a partir de dados de 450 veículos que passaram em frente ao Posto da Polícia Rodoviária Federal posicionado no km 554 da BR-040. 0 modelo de desempenho veicular do VISSIM também exige que sejam informadas distribuições de frequência da aceleração máxima e desejada dos veículos, que foram estabelecidas com o auxílio do TruPer (Demarchi, 2000). Mais detalhes sobre o processo de obtenção do modelo de desempenho veicular para as quatro categorias de veículos pesados podem ser vistos em Lima et al. (2018).

\subsection{Parâmetros comportamentais}

Foram identificados, no VISSIM, 38 parâmetros de submodelos comportamentais, tendo sido aplicado um teste de sensibilidade (Lacerda, 2016) de modo a verificar quais deles são mais relevantes para calibração. Consiste em alterar os parâmetros dos modelos do VISSIM a fim de verificar o impacto nos resultados da simulação. Para isso, foram escolhidos, como medidas de desempenho, a ATS e a Porcentagem de Veículos em Pelotões $(P F)$, por sentido de tráfego. Então, foram calculados Intervalos de Confiança (IC's) das diferenças dos resultados quando cada parâmetro é alterado, em relação aos resultados usando-se os parâmetros default sugeridos pelo VISSIM. Caso os IC's contenham o zero ou sejam pequenos, a influência do parâmetro na medida de desempenho é considerada pequena, levando-se em conta amostras pareadas.

Para a realização da análise de sensibilidade, foram simulados os segmentos entre os km's 95 e 105 (fluxos unidirecionais entre 156 e 608 veic/h), e entre os km's 288 e 298 
(fluxos unidirecionais entre 128 e 319 veic/h), escolhidos por apresentarem as correntes de tráfego com os maiores volumes da amostra coletada em campo, o que favorece o surgimento de interações entre os veículos. No VISSIM, para esses trechos, todos os 38 parâmetros comportamentais foram alterados isoladamente, por duas vezes: usando-se os valores mínimo e máximo do intervalo de busca estabelecido para cada parâmetro. Foram obtidos os resultados de simulação e comparados com os resultados obtidos com os parâmetros default, calculando-se a média, o desvio padrão e o intervalo de confiança das diferenças dos resultados das simulações. Seis parâmetros foram identificados como relevantes para calibração: (i) Look Ahead Maximum Distance (LookAheadDistMax); (ii) Observed Vehicles (ObsrvdVehs); (iii) Safety distance reduction fator - lane change (SafDistFactLnChg); (iv) W99cc1Distr; (v) W99cc3; e (vi) Lateral Minimum Distance at $50 \mathrm{~km} / \mathrm{h}$ (LatDistDrivDef).

Dois desses parâmetros, o LatDistDrivDef e o SafDistFactLnChg, puderam ser obtidos através das filmagens com o drone. De acordo com o Manual do VISSIM (PTV, 2018), o LatDistDrivDef é a distância mínima, em relação à faixa adjacente, mantida pelos veículos que ultrapassam pela faixa do sentido oposto, a $50 \mathrm{~km} / \mathrm{h}$. Para calibrar esse parâmetro, foi observado, com o uso do drone, o comportamento dos veículos quando realizavam as ultrapassagens, capturando-se a distância lateral e a velocidade em que os veículos realizavam as manobras. Foram coletadas informações de 31 manobras de ultrapassagens. A distribuição das distâncias laterais obtidas foi melhor representada pela mediana, devido a assimetria da amostra. Assim, o valor estimado para LatDistDrivDef foi de 1,12 m, valor que é menos agressivo que o valor default do VISSIM, de $1,00 \mathrm{~m}$.

Apesar de relevante, o LatDistDrivDef se mostrou menos impactante na simulação do que o SafDistFactLnChg, que é um fator de redução da distância de segurança desejada para a realização das mudanças de faixa, produto da distância de segurança desejada pelo fator de redução da distância de segurança. Esse fator pode ser definido como a razão da distância final de aproximação do veículo que realiza a ultrapassagem pela distância mantida pelos veículos em following, mas que não desejam realizar ultrapassagens. De posse das 31 ultrapassagens registradas com o drone, foram coletadas as distâncias que os veículos mantiveram quando atrás de outros veículos e foram observadas as distâncias dos veículos que iniciam as ultrapassagens no início da manobra. 0 valor default do VISSIM para o parâmetro é de 0,6, enquanto, para a amostra das ultrapassagens observadas, o parâmetro obtido foi igual a 0,36 (mais agressivo).

Os demais quatro parâmetros relevantes para calibração foram estimados com o uso de um Algoritmo Genético (AG), que é baseado em outro aplicado em estudos anteriores (Bessa Jr. et al., 2017; Bessa Jr. e Setti, 2018). Como citado em Lacerda (2016), se um processo de calibração não for bem delineado, parâmetros comportamentais dos simuladores de tráfego podem ter valores de calibração inadequados (agressivos demais, por exemplo). Sendo assim, outros parâmetros calibrados também podem ser inadequados, mas em outro sentido (muito conservadores, por exemplo), na tentativa de compensar os erros atribuídos aos primeiros parâmetros. A aplicação tradicional dos AG's para calibrar simuladores de tráfego na obtenção dos parâmetros comportamentais é susceptível a esse tipo de erro.

Para diminuir esse problema, a criação da população (de 10 indivíduos) do AG foi baseada no intervalo de busca dos parâmetros de calibração que os compõe, com cada um deles associado a um determinado nível de agressividade: baixo, médio e alto (intervalos de busca divididos em três partes). Cada cromossomo representa um conjunto de parâmetros de calibração que são inseridos nos arquivos de entrada de metade das correntes de tráfego de 
15 minutos obtidas por filmagens. A outra metade foi usada para realizar a validação do AG e, também, para validar os modelos de tráfego obtidos. 0 grau de aptidão (qualidade) de cada indivíduo da população é determinado por meio de uma função objetivo (fitness), a raiz do erro quadrático médio (RMSE), que tem, como principal vantagem, penalizar àquelas soluções que produzem grandes erros absolutos. A formulação de RMSE é dada por:

$$
R M S E=\sqrt{\frac{1}{N} \sum_{i=1}^{n} \sum_{k=1}^{2} \sum_{w=1}^{2}\left(y_{i k w}-x_{i k w}\right)^{2}},
$$

em que $y_{i k w}$ é a velocidade média de viagem (ou velocidade média no espaço) obtida na simulação, para a corrente de tráfego $i$, sentido de tráfego $k$ (leste ou oeste) e tipo de veículo $w$ (automóvel ou veículo pesado); Xikw é a velocidade média de viagem obtida em campo, para a corrente de tráfego $i$, sentido de tráfego $k$ e tipo de veículo $w$; a variável $n$ representa a metade das correntes de tráfego de 15 minutos da amostra; e $N$ representa o total de velocidades médias de viagem avaliadas na amostra (que é igual a $n \times 2 \times 2=4 n$ ).

A velocidade média de viagem foi escolhida como medida-alvo para a calibração e a validação do VISSIM por não ser a medida de desempenho de interesse dos experimentos de simulação (que, neste trabalho, é a $F D$ ). Ela também é influenciada por vários submodelos comportamentais, como os modelos de car-following e de mudança de faixas, além de ser uma variável agregada da corrente de tráfego que é relativamente fácil de ser coletada em campo.

Se a máxima geração (50) não tiver sido atingida, os operadores genéticos são acionados para produzir uma nova geração da população. 0 tipo de seleção de dois indivíduos (pais) para realização de cruzamento (crossover) é baseado na técnica da roleta (Goldberg, 1989), em que a probabilidade de serem selecionados é função do seu grau de adaptação ao meio (fitness). Portanto, quanto menor for o RMSE do indivíduo, mais chance ele tem de ser selecionado para realização de cruzamento. 0 novo cromossomo de um indivíduo da geração seguinte possui genes (parâmetros de calibração) que são resultados da média aritmética dos genes dos seus pais. Os outros operadores genéticos, mutação e predação, que ajudam a inserir diversidade na população, possuem, respectivamente, taxas de 30\% e 20\%, e são aplicadas a cada duas gerações. Com a aplicação do crossover, é possível que alguns genes dos indivíduos de uma nova geração da população tenham agressividades diferentes daquelas definidas no início do processo de calibração (baixo, médio ou alto). Nesses casos, cada gene deve ser substituído por um outro produzido aleatoriamente com base no seu respectivo espaço de busca, de acordo com seu nível de agressividade. Esse processo foi denominado de "alteração genética".

Com relação aos resultados dos parâmetros calibrados pelo AG, todos os valores foram considerados mais agressivos dos que os valores default do VISSIM: LookAheadDistMax = $419 \mathrm{~m}$; ObsrvdVehs = 7 veículos; e W99cc3 = -2,6 s; W99cc1Distr = distribuição dos headways dos veículos quando em regime de following (modelo de Wiedemann 99) com média igual a 0,5 s. A aplicação do AG apresentou uma leve melhora em relação à utilização dos parâmetros default, como pode ser visto no item a seguir.

\subsection{Avaliação do processo de calibração e validação}

Com o intuito de avaliar o efeito de cada passo realizado no processo de calibração e validação do VISSIM, foram analisados os resultados das simulações provenientes dos seguintes cenários:

- Cenário 1: Distribuições de velocidades desejadas, modelos de desempenho veicular e parâmetros comportamentais fornecidos pelo VISSIM (default); 
- Cenário 2: Distribuições de velocidades desejadas obtidos em campo, com os modelos de desempenho veicular e os parâmetros comportamentais em modo default;

- Cenário 3: Distribuições de velocidades desejadas e modelos de desempenho veicular obtidos em campo, e parâmetros comportamentais em modo default; e

- Cenário 4: Todos os parâmetros foram calibrados e validados para as condições locais: distribuições de velocidades desejadas, modelos de desempenho veicular e submodelos comportamentais do VISSIM.

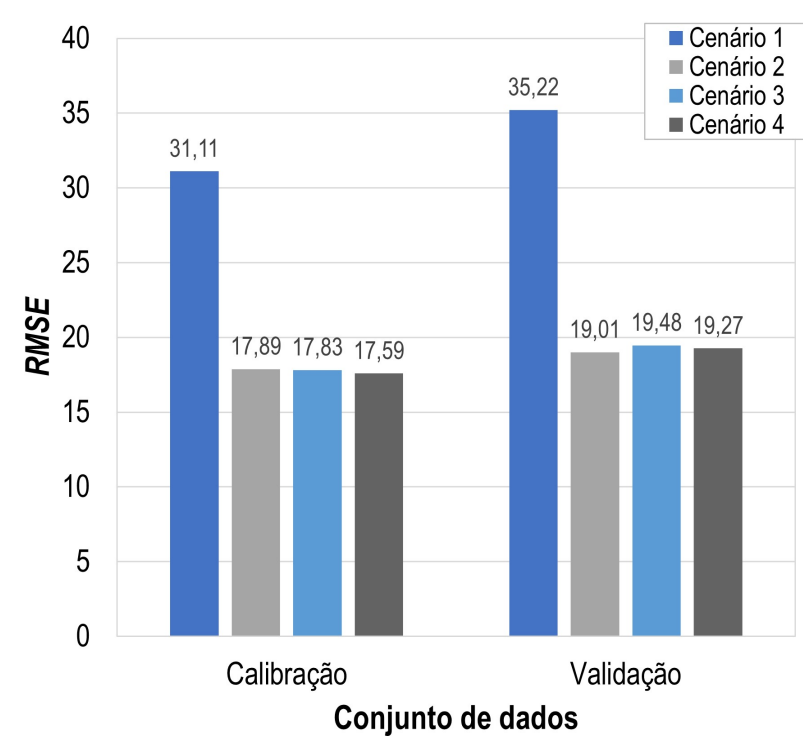

(a)

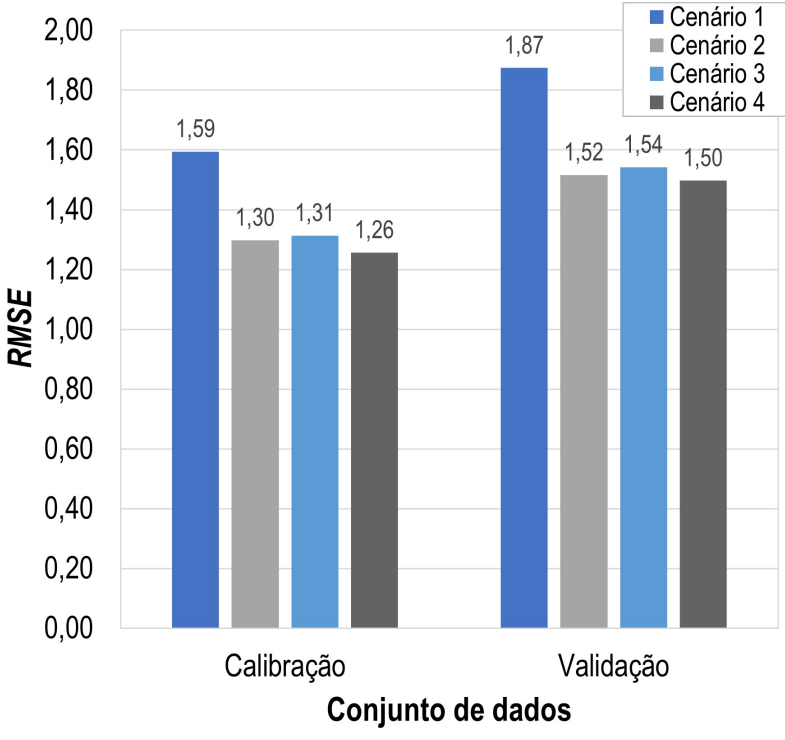

(b)

Figura 4. Valores de RMSE obtidos durante o processo de calibração e de validação do VISSIM, para análise de ATS (a) e de $F D(b)$

Da Figura 4, é possível perceber que o maior impacto ocorreu com a obtenção das distribuições de velocidades desejadas em campo, tanto quando analisada a ATS (medida de desempenho usada na aplicação do AG) como quando foi avaliada a $F D$ (que é a medida de desempenho usada na obtenção dos modelos de tráfego apresentada nas seções a seguir). Analisando-se os cenários mais extremos, o 1 e o 4 - quando todos os parâmetros estão em default e quando todos os parâmetros foram ajustados - percebe-se uma diminuição nos valores de RMSE em $43,5 \%$ quando se avaliou ATS e o conjunto de dados usado na calibração do simulador, resultado que é similar ao que ocorreu com o conjunto de dados da validação (45,30\%), como é visto na Figura 4a. 0 mesmo padrão pode ser observado na Figura $4 \mathrm{~b}$, ao se analisar os resultados de $R M S E$ aplicado à medida de desempenho $F D$. A redução na função objetivo, entre os cenários 1 e 4, foi de $21,2 \%$ para o conjunto de dados da calibração e $20,1 \%$ para os dados usados na validação do simulador. Mais detalhes sobre a calibração e a validação do VISSIM podem ser vistos em Silva (2019).

\section{MODELOS FLUXO X FD}

No relatório do NCHRP Project 17-65, foram propostas cinco classes para representar o alinhamento vertical, em função do comprimento e da rampa do segmento viário. A classe 1 corresponde a um impacto baixo nas condições de tráfego, que vai aumentando até a classe 5 , que apresenta um grande impacto na operação. Da mesma forma, o alinhamento horizontal é 
categorizado em cinco classes, dados em função do raio e da superelevação das curvas. Portanto, as estimativas das medidas de desempenho para cálculo do nível de serviço são realizadas combinando-se segmentos com curva horizontal e em tangente. Neste trabalho, como foi verificado que o impacto das curvas horizontais foi pequeno, conforme ilustrado pelo modelo simplificado da Equação 1, resolveu-se gerar modelos de tráfego apenas considerando-se o efeito das curvas verticais, que impactam mais as correntes de tráfego.

Na proposta do NCHRP Project 17-65, a classificação do alinhamento vertical - ou Classe da Rampa (COG) - é baseada na redução da velocidade de entrada (105 km/h) de um veículo pesado típico num trecho com uma rampa ascendente, da seguinte forma (Washburn et al., 2018): $\mathrm{COG}=1$, para redução na velocidade menores do que $11 \mathrm{~km} / \mathrm{h} ; \mathrm{COG}=2$, para redução na velocidade entre 11 e $23 \mathrm{~km} / \mathrm{h} ; \mathrm{COG}=3$, para redução na velocidade entre 23 e $34 \mathrm{~km} / \mathrm{h}$; COG = 4, para redução na velocidade entre 34 e $45 \mathrm{~km} / \mathrm{h}$; e COG = 5, para redução da velocidade maior ou igual a $45 \mathrm{~km} / \mathrm{h}$. 0 veículo pesado típico usado neste trabalho possuía relação massa/potência de $175 \mathrm{~kg} / \mathrm{kW}$, que representa o 85을 percentil da distribuição de veículos pesados da amostra obtida numa balança móvel da BR-040 (Lima et al., 2018). Considera-se que, para obter o COG das descidas, se deve subtrair 1 unidade ao COG encontrado para as subidas quando a diferença entre os valores das velocidades de equilíbrio na descida e na subida de mesma declividade (em módulo) é maior do que $20 \mathrm{~km} / \mathrm{h}$. Dessa forma, a Tabela 1 ilustra os COGs encontrados em função do comprimento e da inclinação da rampa.

Tabela 1 - Classificação do alinhamento vertical

\begin{tabular}{|c|c|c|c|c|c|c|c|c|c|c|c|c|c|c|c|c|c|c|}
\hline \multirow{3}{*}{$\begin{array}{l}\text { Comprimento do } \\
\text { segmento }(\mathrm{m})\end{array}$} & \multicolumn{18}{|c|}{ Rampa (\%) } \\
\hline & 1 & -1 & 2 & -2 & 3 & -3 & 4 & -4 & 5 & -5 & 6 & -6 & 7 & -7 & 8 & -8 & 9 & -9 \\
\hline & \multicolumn{18}{|c|}{ Classe da rampa (COG) } \\
\hline$\leq 200$ & 1 & 1 & 1 & 1 & 1 & 1 & 1 & 1 & 1 & 1 & 1 & 1 & 1 & 1 & 1 & 1 & 2 & 2 \\
\hline$\geq 200<400$ & 1 & 1 & 1 & 1 & 2 & 2 & 2 & 2 & 2 & 1 & 3 & 2 & 3 & 3 & 4 & 3 & 4 & 4 \\
\hline$\geq 400<600$ & 1 & 1 & 2 & 2 & 2 & 2 & 3 & 3 & 4 & 4 & 4 & 4 & 5 & 5 & 5 & 4 & 5 & 5 \\
\hline$\geq 600<800$ & 1 & 1 & 2 & 2 & 3 & 2 & 4 & 4 & 5 & 4 & 5 & 5 & 5 & 5 & 5 & 4 & 5 & 5 \\
\hline$\geq 800<1000$ & 2 & 2 & 3 & 3 & 4 & 3 & 5 & 4 & 5 & 4 & 5 & 5 & 5 & 5 & 5 & 5 & 5 & 5 \\
\hline$\geq 1000<1200$ & 2 & 2 & 3 & 3 & 4 & 3 & 5 & 4 & 5 & 4 & 5 & 5 & 5 & 5 & 5 & 5 & 5 & 5 \\
\hline$\geq 1200<1400$ & 2 & 2 & 3 & 3 & 5 & 4 & 5 & 5 & 5 & 5 & 5 & 4 & 5 & 5 & 5 & 5 & 5 & 5 \\
\hline$\geq 1400<2400$ & 3 & 3 & 5 & 5 & 5 & 4 & 5 & 5 & 5 & 5 & 5 & 5 & 5 & 5 & 5 & 5 & 5 & 5 \\
\hline$\geq 2400$ & 3 & 3 & 5 & 5 & 5 & 5 & 5 & 5 & 5 & 5 & 5 & 5 & 5 & 5 & 5 & 5 & 5 & 5 \\
\hline
\end{tabular}

A FD (veic $/ \mathrm{km}$ ), medida de desempenho que foi proposta no NCHRP Project 17-65 como alternativa à ATS e à PTSF como medidas de serviço voltadas para rodovias de pista simples, reflete a proximidade dos veículos, as oportunidades de realização de manobras de ultrapassagens e o desconforto dos motoristas ao trafegarem em pelotões. Ela é calculada, para um sentido de tráfego, pela seguinte equação:

$$
F D=\frac{P F}{100} \cdot \frac{V_{d}}{A T S},
$$

em que $P F$ é a porcentagem de veículos em pelotões; $v_{d}$ é o fluxo de tráfego (cpe/h); e ATS é a velocidade média de viagem $(\mathrm{km} / \mathrm{h})$.

Neste trabalho, com a obtenção das classes do alinhamento vertical, foram desenvolvidos modelos que correlacionavam fluxo unidirecional $\left(q_{d}\right)$, em veic/h, e $F D$, em função de COG, porcentagem de veículos pesados $\left(P_{h v}\right)$ e velocidade de fluxo livre $(F F S)$. Foram criados, no VISSIM, 10 segmentos viários hipotéticos de $10 \mathrm{~km}$ para cada COG, alternando-se segmentos de subida e de descida, em tangente, com a inclinação e o comprimento definidos randomicamente em 
função da Tabela 1. Os trechos hipotéticos foram usados para gerar modelos: (i) sem faixas adicionais e sem proibição de ultrapassagens (aqui denominados de "modelos base"); e (ii) com a inserção de faixas adicionais nos subsegmentos em subida, realizada de acordo com Melo e Setti (2007). Mais detalhes sobre a inclusão das faixas adicionais nos subsegmentos podem ser encontrados em Silva (2019).

A FFS foi simulada de 70 a $110 \mathrm{~km} / \mathrm{h}$, variando-se de $10 \mathrm{em} 10 \mathrm{~km} / \mathrm{h}$. Para as porcentagens de veículos pesados $\left(P_{h v}\right)$, foram considerados de $0 \%$ a $50 \%$ da corrente de tráfego, variando-se de $10 \%$ em 10\%. Considerando as cinco categorias de alinhamento vertical, foram realizadas, portanto, 5 × 6 × $5=150$ relações fluxo- $F D$ unidirecionais. Para produzir cada um desses modelos, foram simuladas 100 correntes de tráfego, o que resultou em 100 x $150=15.000$ simulações no total. Foi utilizado um modelo quadrático entre $q_{d}$ e $F D_{d}$ (FGSV, 2005; Bessa Jr. e Setti, 2018):

em que $a$ é um parâmetro de calibração.

$$
F D_{d}=a \cdot q_{d}^{2}
$$

Na Tabela 2, é possível verificar exemplos de parâmetros a (Equação 4), encontrados para $P_{h v}$ iguais a 10\%, 20\% e 30\%. Independentemente do valor de FFS, percebe-se que um COG = 1 fornece maiores valores do parâmetro $a$ (e, consequentemente, de $F D$ ) do que para COG $=2$, quando, a partir daí, com o crescimento do COG, os valores do parâmetro crescem progressivamente. Esse padrão descontínuo com o crescimento do COG também pode ser visto em Washburn et al. (2018), para parâmetros de calibração de diferentes relações de tráfego para estimar a FD (ou medidas de desempenho correlacionadas, como a ATS). Para cada COG, os parâmetros $a$ decrescem quando a FFS cresce, o que era esperado, pois os veículos tendem a manter maiores headways quando a velocidade é maior.

Tabela 2 - Parâmetros dos modelos base de $F D_{d}$, para $P_{h v}$ iguais a $10 \%, 20 \%$ e $30 \%$

\begin{tabular}{|c|c|c|c|c|c|c|c|c|c|c|}
\hline \multicolumn{11}{|c|}{$P_{h v}=10 \%$} \\
\hline \multirow{2}{*}{$F F S(\mathrm{~km} / \mathrm{h})$} & \multicolumn{2}{|c|}{ COG $=1$} & \multicolumn{2}{|c|}{$\mathrm{COG}=2$} & \multicolumn{2}{|c|}{$\mathrm{COG}=3$} & \multicolumn{2}{|c|}{$\mathrm{COG}=4$} & \multicolumn{2}{|c|}{$\mathrm{COG}=5$} \\
\hline & $\mathrm{a}$ & $R^{2}$ & a & $R^{2}$ & $\mathrm{a}$ & $R^{2}$ & a & $R^{2}$ & $\mathrm{a}$ & $R^{2}$ \\
\hline 70 & 0,0000082 & 0,9858 & 0,0000069 & 0,9288 & 0,0000077 & 0,9524 & 0,0000114 & 0,9662 & 0,0000115 & 0,9703 \\
\hline 80 & 0,0000079 & 0,9770 & 0,0000067 & 0,9462 & 0,0000074 & 0,9648 & 0,0000109 & 0,9499 & 0,0000110 & 0,9504 \\
\hline 90 & 0,0000077 & 0,9718 & 0,0000066 & 0,9384 & 0,0000073 & 0,9711 & 0,0000108 & 0,9746 & 0,0000110 & 0,9565 \\
\hline 100 & 0,0000073 & 0,9648 & 0,0000063 & 0,9429 & 0,0000070 & 0,9615 & 0,0000103 & 0,9808 & 0,0000106 & 0,9895 \\
\hline 110 & 0,0000073 & 0,9590 & 0,0000063 & 0,9174 & 0,0000070 & 0,9595 & 0,0000102 & 0,9597 & 0,0000104 & 0,9757 \\
\hline \multicolumn{11}{|c|}{$P_{h v}=20 \%$} \\
\hline \multirow{2}{*}{$F F S(\mathrm{~km} / \mathrm{h})$} & \multicolumn{2}{|c|}{$\mathrm{COG}=1$} & \multicolumn{2}{|c|}{$\mathrm{COG}=2$} & \multicolumn{2}{|c|}{$\mathrm{COG}=3$} & \multicolumn{2}{|c|}{$\mathrm{COG}=4$} & \multicolumn{2}{|c|}{$\mathrm{COG}=5$} \\
\hline & $\mathrm{a}$ & $R^{2}$ & a & $R^{2}$ & $\mathrm{a}$ & $R^{2}$ & a & $R^{2}$ & $\mathrm{a}$ & $R^{2}$ \\
\hline 70 & 0,0000083 & 0,9742 & 0,0000070 & 0,9845 & 0,0000078 & 0,9336 & 0,0000112 & 0,9524 & 0,0000115 & 0,9687 \\
\hline 80 & 0,0000080 & 0,9724 & 0,0000067 & 0,9753 & 0,0000074 & 0,9487 & 0,0000110 & 0,9678 & 0,0000113 & 0,9496 \\
\hline 90 & 0,0000080 & 0,9672 & 0,0000067 & 0,9708 & 0,0000074 & 0,9416 & 0,0000109 & 0,9740 & 0,0000111 & 0,9780 \\
\hline 100 & 0,0000078 & 0,9304 & 0,0000065 & 0,9646 & 0,0000071 & 0,9448 & 0,0000103 & 0,9605 & 0,0000107 & 0,9825 \\
\hline 110 & 0,0000077 & 0,9884 & 0,0000064 & 0,9601 & 0,0000071 & 0,9213 & 0,0000100 & 0,9606 & 0,0000103 & 0,9606 \\
\hline \multicolumn{11}{|c|}{$P_{h v}=30 \%$} \\
\hline \multirow{2}{*}{$F F S(\mathrm{~km} / \mathrm{h})$} & \multicolumn{2}{|c|}{$\mathrm{COG}=1$} & \multicolumn{2}{|c|}{$\mathrm{COG}=2$} & \multicolumn{2}{|c|}{$\mathrm{COG}=3$} & \multicolumn{2}{|c|}{$\mathrm{COG}=4$} & \multicolumn{2}{|c|}{$\mathrm{COG}=5$} \\
\hline & a & $R^{2}$ & a & $R^{2}$ & a & $R^{2}$ & a & $R^{2}$ & a & $R^{2}$ \\
\hline 70 & 0,0000082 & 0,9695 & 0,0000075 & 0,9741 & 0,0000073 & 0,9855 & 0,0000101 & 0,9382 & 0,0000114 & 0,9550 \\
\hline 80 & 0,0000079 & 0,9550 & 0,0000072 & 0,9717 & 0,0000072 & 0,9769 & 0,0000101 & 0,9506 & 0,0000111 & 0,9722 \\
\hline 90 & 0,0000079 & 0,9576 & 0,0000072 & 0,9670 & 0,0000072 & 0,9731 & 0,0000100 & 0,9474 & 0,0000110 & 0,9780 \\
\hline 100 & 0,0000077 & 0,9889 & 0,0000070 & 0,9351 & 0,0000070 & 0,9625 & 0,0000096 & 0,9485 & 0,0000107 & 0,9680 \\
\hline 110 & 0,0000075 & 0,9780 & 0,0000068 & 0,9884 & 0,0000068 & 0,9600 & 0,0000095 & 0,9252 & 0,0000105 & 0,9633 \\
\hline
\end{tabular}

Os valores de $F D$ aumentam quando o $P_{h v}$ aumenta até certo ponto, quando o parâmetro $a$, então, começa a cair. Tomando o $\mathrm{COG}=3$ como exemplo, é possível perceber que os valores de $F D$ atingem esse pico quando o $P_{h v}$ é igual a $30 \%$. Isso deve ocorrer porque, quando o $P_{h v}$ começa 
a crescer muito, as oportunidades de ultrapassagens começam a diminuir, fazendo com que os veículos mais rápidos sejam mais cautelosos na realização das manobras, evitando se aproximar muito dos pelotões (assim, os valores de $F D$ diminuem um pouco). Os valores intermediários de $a$ para valores de COG, $P_{h v}$ e FFS diferentes dos apresentados na Tabela 2 devem ser obtidos por meio de interpolação linear. Parâmetros a para valores de $P_{h v}$ diferentes de 10\%, 20\% e 30\%, em função de COG e FFS, podem ser vistos em Silva (2019).

Não foi identificada a necessidade de implantação de faixa adicional de subida em nenhum trecho com $C O G=1$, pois o desempenho dos caminhões é menos afetado pelas rampas, que, por consequência, são mais suaves ou curtas que a das outras classes de alinhamento vertical. Com os resultados das simulações para trechos com faixas adicionais, foram realizadas regressões considerando-se o modelo da Equação 4, com a obtenção de outros parâmetros $a$. Foram calculados fatores de ajuste para as faixas adicionais de subida, $f_{f a}$, que consistem na diferença entre a $F D_{d}$ do modelo base pela $F D_{f a s}$ ( $F D$ com faixas adicionais):

$$
f_{f a}=F D_{d}-F D_{f a s} .
$$

Tabela 3 - Fatores de ajuste para faixas adicionais de subida, com COG = 4 e FFS = $110 \mathrm{~km} / \mathrm{h}$

\begin{tabular}{ccccccc}
\hline & \multicolumn{7}{c}{$P_{h v}(\%)$} \\
\cline { 2 - 7 } $\mathrm{q}_{d}($ veic/h) & 0 & 10 & 20 & 30 & 40 & 50 \\
\cline { 2 - 7 } & 0,0566 & 0,0984 & 0,0987 & 0,0945 & 0,0941 & 0,0925 \\
\hline 200 & 0,2262 & 0,3938 & 0,3950 & 0,3781 & 0,3765 & 0,3701 \\
400 & 0,5090 & 0,8860 & 0,8887 & 0,8507 & 0,8471 & 0,8327 \\
600 & 0,9049 & 1,5750 & 1,5800 & 1,5123 & 1,5060 & 1,4804 \\
800 & 1,4138 & 2,4610 & 2,4687 & 2,3630 & 2,3531 & 2,3131 \\
1000 & 2,0359 & 3,5438 & 3,5550 & 3,4028 & 3,3885 & 3,3309 \\
1200 & 2,7711 & 4,8235 & 4,8387 & 4,6315 & 4,6121 & 4,5337 \\
1400 & 3,6194 & 6,3001 & 6,3200 & 6,0493 & 6,0239 & 5,9216 \\
1600 & 4,5809 & 7,9736 & 7,9987 & 7,6562 & 7,6240 & 7,4945 \\
1800 & & 7
\end{tabular}

Na Tabela 3, é possível verificar exemplos de valores de $f_{f a}$, para COG $=4$ e $F F S=110 \mathrm{~km} / \mathrm{h}$. Os valores intermediários de $f_{f a}$ para valores de $P_{h v}$ e FFS diferentes dos apresentados na Tabela 3 devem ser obtidos por meio de interpolação linear. Valores para outras combinações de COG, $P_{h v}$ e FFS podem ser vistos em Silva (2019).

Na Figura 5, observam-se exemplos do modelo base e do modelo com faixas adicionais, para $F F S=110 \mathrm{~km} / \mathrm{h}, P_{h v}=50 \%$ e COG $=2$ e 5.0 impacto das faixas adicionais foi mais evidente de acordo com as combinações dos parâmetros do modelo $F F S, P_{h v}$ e $q_{d}$, mas, principalmente, em função do COG, pois o relevo impacta mais os veículos, especialmente os pesados. Para o $\mathrm{COG}=2$, a faixa adicional apresentou pouca influência no resultado da $F D_{d}$, com a maior redução na $F D_{d}$ obtida com $P_{h v}=20 \%$ para todas as $F F S$. Com COG $=5$, os maiores $f_{f a}$ foram percebidos com $P_{h v}=20 \%$ para todos as FFS, com exceção da $F F S .=110 \mathrm{~km} / \mathrm{h}$, em que o maior efeito foi observado com $P_{h v}=30 \%$. Foi possível observar também que os menores impactos da faixa adicional ocorreram, geralmente, com $P_{h v}=50 \%$. Isso ocorre porque, com uma maior presença de veículos pesados, a eficiência da faixa adicional é comprometida, haja vista a necessidade de os veículos mais leves aguardarem os veículos pesados se manterem à direita para que ocorra a dispersão dos pelotões e o aumento da velocidade média, proporcionando um menor valor de $F D$. 

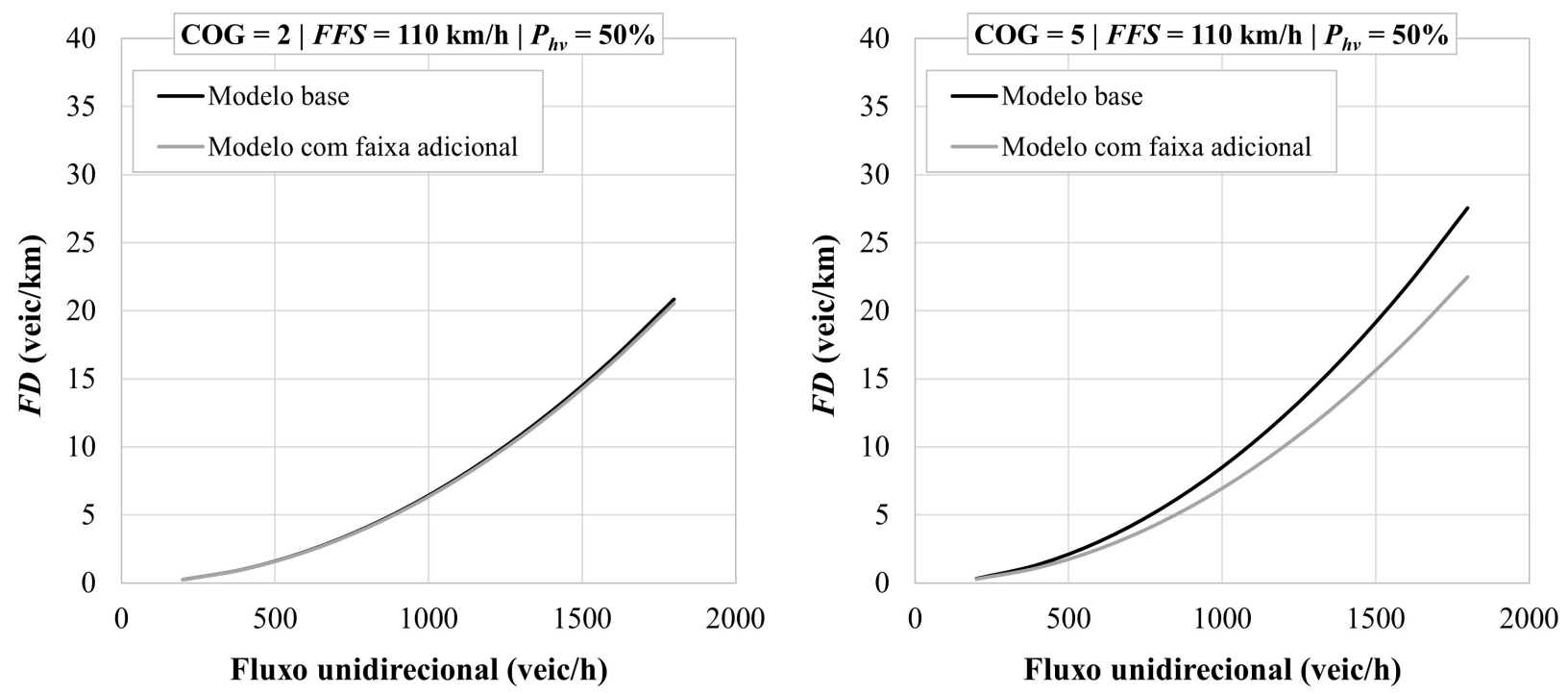

Figura 5. Exemplos de modelo base e de modelo com faixas adicionais para $F F S=110 \mathrm{~km} / \mathrm{h}, P_{h v}=50 \%$ e $C O G=2$ e 5

\section{DEFINIÇÃO DO NÍVEL DE SERVIÇO E VALIDAÇÃO DOS MODELOS}

Foi proposto um critério de determinação do nível de serviço para rodovias de pistas simples a partir de $F D_{d}$, baseado na proposta de Li e Washburn (2014). 0 método consiste, primeiro, em encontrar os volumes que determinam a mudança entre os níveis de serviço (A a E) para uma relação fluxo-FD que serve de base - neste trabalho, proveniente da proposta do NCHRP Project 17-65 - em condições bem favoráveis (COG $=1$ e $P_{h v}=0 \%$, tendo sido usado o modelo com $F F S=70 \mathrm{~km} / \mathrm{h}$ ). Em seguida, para cada um desses volumes de serviço encontrados, determinase, usando o modelo fluxo-FD proposto neste trabalho (também com COG $=1, P_{h v}=0 \%$ e $F F S=70 \mathrm{~km} / \mathrm{h}$ ), os valores de $F D_{d}$ correspondentes. Esses valores determinam os intervalos dos diferentes níveis de serviço, como ilustrado na Tabela 4, em que é possível encontrar também o critério do NCHRP Project 17-65. Vale ressaltar que esse método é aplicado somente para essas condições favoráveis, partindo-se do princípio de que, para as demais condições, o critério encontrado para determinar o nível de serviço também é válido.

Tabela 4 - Critérios de obtenção de nível de serviço em função de $F D$

\begin{tabular}{llll}
\hline \multirow{2}{*}{ Nível de Serviço } & $\begin{array}{l}\text { Critério proposto } \\
\left(F D_{d} \text { Quadrático }\right)\end{array}$ & $\begin{array}{l}\text { Rodovias com } \\
\text { velocidade regulamentar } \geq 80 \mathrm{~km} / \mathrm{h}\end{array}$ & $\begin{array}{l}\text { Rodovias com } \\
\text { velocidade regulamentar } \leq 80 \mathrm{~km} / \mathrm{h}\end{array}$ \\
\cline { 3 - 4 } & $\leq 1,2$ & $\leq 3,2$ & $\leq 4$ \\
$\mathrm{~A}$ & $>1,2-2,7$ & $>3,2-6,4$ & $>4-8$ \\
$\mathrm{~B}$ & $>2,7-4,7$ & $>6,4-12,8$ & $>8-16$ \\
$\mathrm{D}$ & $>4,7-7,4$ & $>12,8-19,2$ & $>16-24$ \\
$\mathrm{E}$ & $>7,4$ & $>19,2$ & $>24$ \\
\hline
\end{tabular}

Para comparar cada um dos critérios, foram calculados os valores de FDd e os níveis de serviços de metade das correntes de tráfego obtidas em campo da amostra de validação do VISSIM (dados obtidos por filmagem). A outra metade, usada na calibração do simulador, tem forte influência sobre os modelos fluxo versus FD estimados a partir de dados gerados por simulação e, portanto, não faz sentido usá-la para avaliar as relações de tráfego propostas. Conforme demonstrado na Figura 6, os dados de $F D_{d}$ encontrados neste trabalho, para diferentes combinações de COG, FFS e $P_{h v}$, estiveram mais próximos dos dados de campo do que aqueles 
encontrados com o modelo do NCHRP Project 17-65.

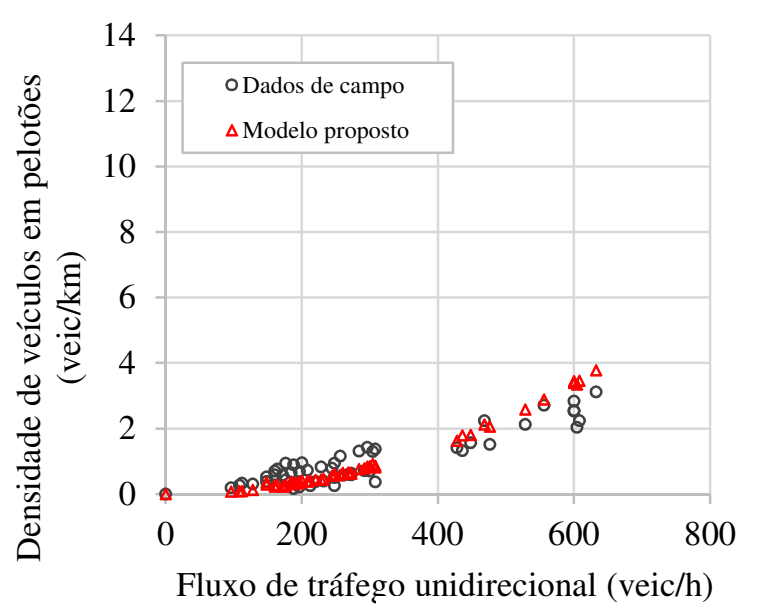

(a)

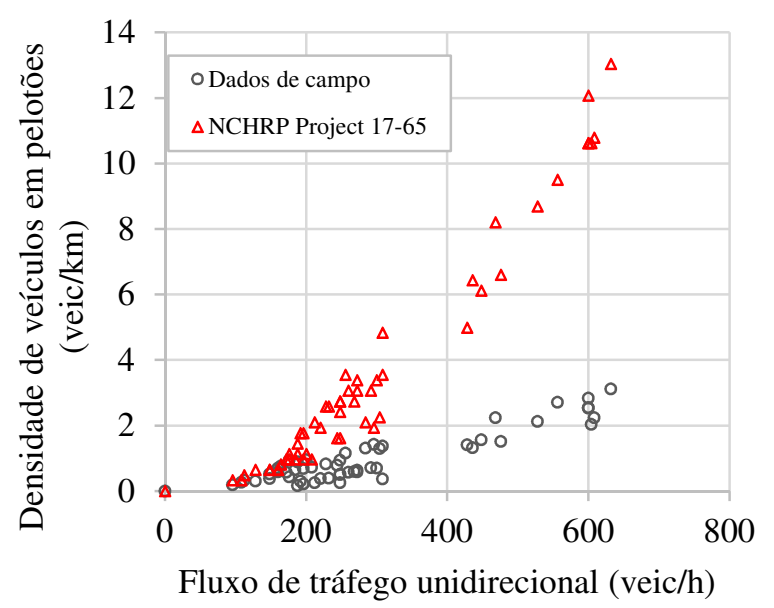

(b)

Figura 6. Medidas de desempenho obtidas em campo e obtidas com o modelo proposto (a) e com o NCHRP Project 17-65 (b)

Conforme apresentado no gráfico de bolhas da Figura 7, foram obtidos os níveis de serviços considerando cada uma das classificações propostas na Tabela 4. Os modelos e o critério propostos neste trabalho apresentaram níveis de serviço bastante próximos em relação aos observados em campo. Por outro lado, a proposta do NCHRP Project 17-65 subestima o nível de serviço de campo. Esse resultado demostra que, se utilizar o HCM sem nenhum tipo de adaptação, o que é comum, os níveis de serviço obtidos tendem a ser piores do que, de fato, são, pelo menos para os casos estudados neste trabalho.

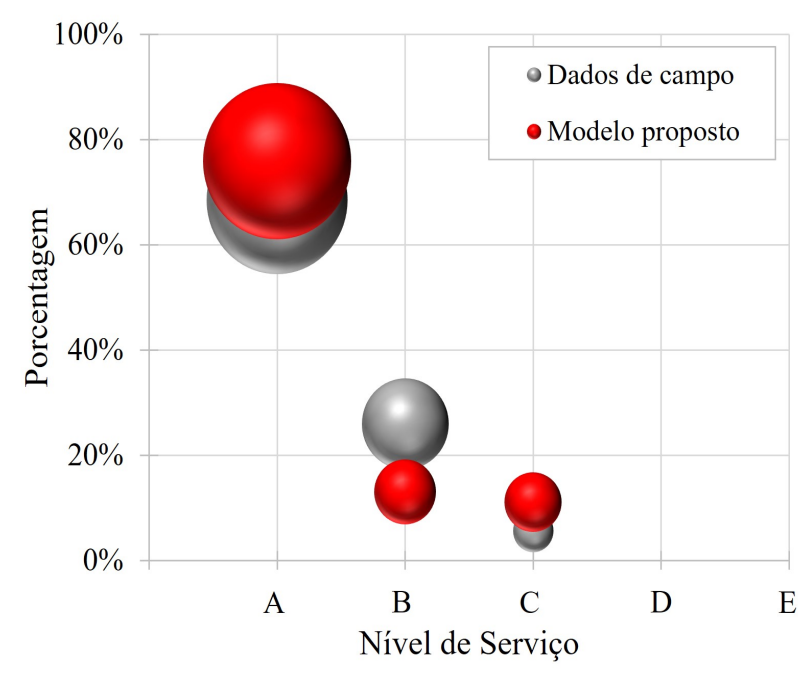

(a)

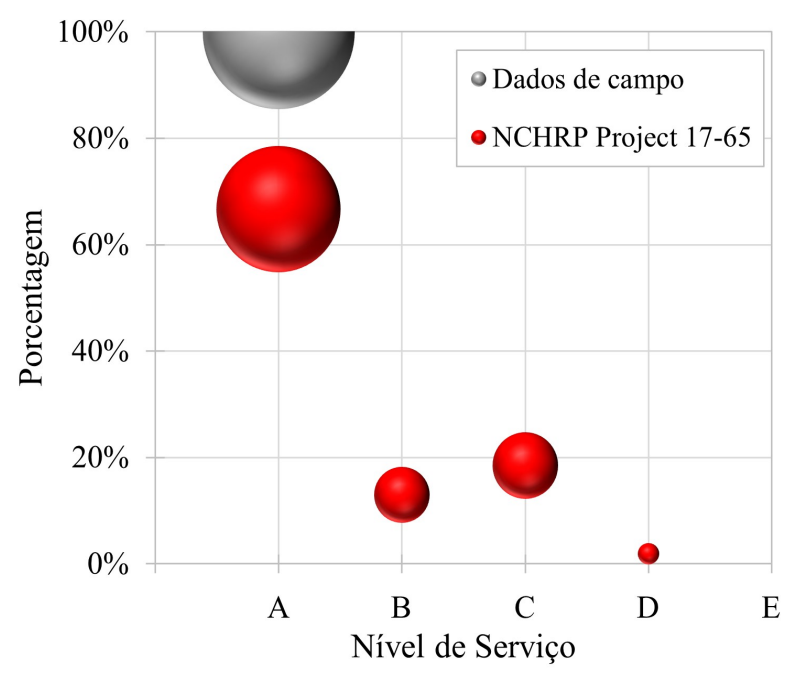

(b)

Figura 7. Níveis de serviço obtidos em campo e obtidos com os critérios e modelos proposto (a) e do NCHRP Project 17-65 (b)

\section{CONSIDERAÇÕES FINAIS}

Este trabalho teve, como objetivo principal, estimar o impacto das faixas adicionais de subida na operação de rodovias de pista simples. 0 simulador VISSIM foi calibrado para produzir 
modelos de tráfego com e sem faixas adicionais. A geometria viária foi tratada por meio de cinco classes do alinhamento vertical, denominado de COG. Foram gerados segmentos viários hipotéticos e gerados dados por simulação, utilizados para obter modelos de tráfego. Os resultados dessa análise indicaram que o modelo proposto entre fluxo unidirecional e $F D$ produziram valores de nível de serviço e de $F D$ mais aderentes ao que foram observados em campo.

A utilização do novo método do HCM - sem nenhuma adaptação - tende a subestimar o nível de serviço em rodovias brasileiras, o que provocaria investimentos antes do momento adequado. De modo geral, pode-se perceber que, com valores de $P_{h v}$ elevados ( $40 \%$ e 50\%), a densidade de veículos em pelotões é menos influenciada pela faixa adicional. Para diferentes valores de $P_{h v}$ e valores de COGs iguais a 1 e 2, a faixa adicional não produz grandes efeitos na redução de $F D_{d}$. Para COGs iguais a 4 e 5, fica evidente o benefício das faixas adicionais na redução da densidade de veículos em pelotões, principalmente para valores de $P_{h v}$ de até $30 \%$.

Para trabalhos futuros, é recomendável obter um conjunto de dados de tráfego específico para o comportamento dos condutores em curvas horizontais e, então, verificar precisamente o impacto na $F D$. Neste trabalho, foi obtido um conjunto pequeno de informações em curvas horizontais, sendo importante obter dados com uma maior diversidade (inclusive com rampas mais íngremes e raios menores do que as observadas neste trabalho). É recomendável, ainda, ampliar as informações sobre os veículos pesados, em especial o comportamento desses veículos em curvas horizontais e, também, a respeito da velocidade desejada por categoria de veículo pesado, pois o VISSIM permite que seja atribuída essa informação para cada tipo de veículo. Um estudo também poderia ser conduzido para segmentos com faixas de ultrapassagens sem aclives.

Considerando-se a quantidade de fatores de ajustes e a complexidade para obtenção da densidade de veículos em pelotões propostos pelo NCHRP Project 17-65, um outro estudo seria adaptar o novo método para condições de rodovias brasileiras, mantendo-se a estrutura proposta para o HCM.

\section{AGRADECIMENTOS}

Os autores agradecem à FAPEMIG, pelo apoio financeiro sob número de processo APQ-03779-16, ao CNPq, pelo apoio financeiro sob os números de processo 312651/2018-0 e 439250/2018-8, e à CAPES, pelo apoio à pesquisa. 0 presente trabalho também foi realizado com apoio dos Recursos de Desenvolvimento Tecnológico (RDT), da Concessionária Via040, sob regulação da Agência Nacional de Transportes Terrestres (ANTT).

\section{REFERÊNCIAS}

AASHTO (2011) A policy on geometric design of highways and streets, $6^{\text {th }}$ Edition. American Association of State Highway and Transportation Officials, Washington.

Al-Kaisy, A.; A. Jafari e S. S. Washburn (2017) Measuring performance on two-lane highways - Empirical investigation. Transportation Research Record: Journal of the Transportation Research Board, v. 2615, n. 1, p. 62-72. D0I: 10.3141/2615-08.

Al-Kaisy, A. e Z. Freedman (2011) Empirical examination of passing lane operational benefits on rural two-lane highways. 6th International Symposium on Highway Capacity and Quality of Service. Procedia Social and Behavioral Sciences, v. 16, p. 340-351. DOI: 10.1016/j.sbspro.2011.04.455.

ANAC (2017) Regulamento brasileiro de aviação civil especial - RBAC -E no 94. Agência Nacional de Aviação Civil.

Bessa Jr., J. E e J. R. Setti (2018) Evaluating measures of effectiveness for quality of service estimation on two-lane rural highways. Journal of Transportation Engineering, Part A: Systems, v. 144, p. 04018056. DOI: 10.1061/JTEPBS.0000178.

Bessa Jr, J. E.; J. R. Setti e S. S. Washburn (2017) Evaluation of models to estimate percent time spent following on two-lane highways. Journal of Transportation Engineering, Part A: Systems, v. 143, p. 04017010. DOI: 10.1061/JTEPBS.0000032.

Cunha, A. L. B. N. (2013) Sistema automático para obtenção de parâmetros do tráfego veicular a partir de imagens de vídeo usando OpenCV. Tese de Doutorado, Escola de Engenharia de São Carlos, Universidade de São Paulo. Disponível em: <https://www.teses.usp.br/teses/disponiveis/18/18144/tde-19112013-165611/pt-br.php> (acesso em 20/08/2021).

Demarchi, S. H. (2000) TruPer simulador de desempenho de veículos rodoviários e ferroviários. Departamento de Engenharia Civil, Universidade Estadual de Maringá.

DJI (2017) Mavic Pro: User manual, Shenzhen, Guangdong, China. 
FGSV (2005) Handbuch zur Bemessung von Strassenverkehrsanlagen 2001 (HBS, German Highway Capacity Manual 2001). Forschungsgesellschaft fur Straßen und Verkehrswesen (FGSV), Cologne.

Goldberg, D. E. (1989) Genetic algorithms in search, optimization and machine learning. Addison-Wesley, Reading, Massachusetts.

Hollander, Y. e R. Liu (2008) The principles of calibrating traffic microsimulation models. Transportation, v. 35, n. 3, p. 347362. DOI: $10.1007 / \mathrm{s} 11116-007-9156-2$.

Lacerda, V. M. (2016) Estimação da velocidade média em vias urbanas com o uso do microssimulador VISSIM. Dissertação de Mestrado. Universidade Federal do Ceará. Disponível em: <http://www.repositorio.ufc.br/handle/riufc/31543> (acesso em 09/08/2021).

Li, J e S. S. Washburn (2014) Improved operational performance assessment for two-lane highway facilities. Journal of Transportation Engineering. v. 140, n. 6. DOI: 10.1061/(ASCE)TE.1943-5436.0000666.

Lima, C. M.; L. V. Fleury; F. A. Silva; J. E. Bessa Jr.; A. L. Costa; D. M. C. Velho e A. F. Andalício (2018) Caracterização da frota de caminhões da rodovia BR-040 para fins de simulação microscópica com o VISSIM. Anais do XXXII Congresso de Pesquisa e Ensino em Transportes. Gramado, RS.

Melo, R. A. e J. R. A. Setti (2007) Fluxos mínimos de veículos para implantação de faixas adicionais em aclives de rodovias de pista simples. Transportes, v. 15, n. 1, p. 16-23. DOI: 10.14295/transportes.v15i1.43.

Moreno, A. T. (2020) Estimating traffic performance on Spanish two-lane highways. Case study validation. Case Studies on Transport Policy, v. 8, n. 1, p. 119-126. DOI: 10.1016/j.cstp.2018.06.005.

Moreno, A. T.; C. Llorca e A. García (2016) Operational impact of horizontal and vertical alignment of two-lane highways. Transportation Research Procedia, v. 15, p. 319-330. DOI: 10.1016/j.trpro.2016.06.027.

Moreno, A. T.; C. Llorca; S. S. Washburn; J. E. Bessa Jr. e A. García (2018) Operational considerations of passing zones for twolane highways: Spanish case study. Promet-Traffic \& Transportation, v. 30, n. 5, p. 601-612. DOI: 10.7307/ptt.v30i5.2776.

Pereira, H. M. e J. E. Bessa Jr. (2017) Análise comparativa de métodos para cálculo do nível de serviço em rodovias de pista simples. Anais do XXXI Congresso de Pesquisa e Ensino em Transportes. Recife, PE.

PTV (2018) VISSIM 10 User Manual. Planning Transport Verkehr AG - PTV Vision, Karlsruhe, Germany.

Setti, J. R.; J. E. Bessa Jr.; C. Y. Egami e M. L. Mon-Ma (2011) Adaptação do HCM2000 para análise da capacidade e do nível de serviço em rodovias de pista simples no Brasil. Transportes, v. 19, n. 2, p. 66-78. DOI: 10.14295/transportes.v19i2.510.

Silva, F. A. (2019) Determinação do impacto de zonas de ultrapassagens proibidas e de faixas adicionais de subida em segmentos de rodovias de pista simples. Dissertação de Mestrado. Escola de Engenharia, Universidade Federal de Minas Gerais. Disponível em: <http://hdl.handle.net/1843/30497> (acesso em 09/08/2021).

TRB (2000) Highway Capacity Manua 2000. Transportation Research Board. Washington D.C.

TRB (2016) Highway Capacity Manual, $6^{\text {th }}$ edition: a guide for multimodal mobility analysis. Transportation Research Board. Washington D.C.

TSS (2018) Aimsun 8.3: Dynamic Simulators User's Manual. Transport Simulation Systems. Barcelona, Espanha.

Utimura, F. S.; J. R. Setti; C. Y. Egami e M. L. Mon-Ma (2007) Verificação da acurácia de estimativas do nível de serviço em rodovias de pista simples no estado de São Paulo. In: XXI Congresso de Pesquisa e Ensino em Transportes, 2007, Rio de Janeiro. Panorama Nacional da Pesquisa em Transportes 2007. Rio de Janeiro: ANPET.

Washburn, S. S. (2017) SwashSim Traffic Simulation Program, User guide for the two-lane highway module. University of Florida, 2017.

Washburn, S. S.; D. Watson; Z. Bian; T. Luttinen; A. Al-Kaisy; A. Jafari; R. Dowling e A. Elias (2018) Improved analysis of two-lane highway capacity and operational performance. Final Report for NCHRP Project 17-65 National Cooperative Highway Research Program, TRB, Washington, Web-Only Document 255. DOI: 10.17226/25179. 